\title{
STUDY OF A CASE OF PAROXYSMAL HEMOGLOBINURIA
}

\author{
SERUM REACTIONS: UROBILIN AND HEMOGLOBIN EXCRETION *
}

\author{
CHARLES C. DENNIE, M.D., AND OSWALD H. ROBERTSON, M.D. \\ BOSTON \\ SAN FRANCISCO
}

The uncertain nature of the hemolytic reaction characteristic of paroxysmal hemoglobinuria presents a problem of continued interest. The majority of investigators are agreed that the theory originally put forward by Donath and Landsteiner ${ }^{1}$ explains in a general way the mechanism by which a paroxysm is brought about. But concerning the number and character of the different factors involved and the physical conditions under which they act, there are almost as many opinions as there are writers.

The first part of the paper is a study of this reaction. The second part deals with the quantity of blood destroyed during an experimental exposure to cold and the rapidity of the consequent excretion of hemoglobin by the kidneys.

As the literature contains many clinical descriptions of this condition, only a short history will be given and enough of the physical findings to establish the diagnosis and corroborate the data given by other investigators.

History and Physical Findings.-C. S. R., boy, aged 12, colored, entered South Medical Service of the Massachusetts General Hospital, Nov. 18, 1914. Father and mother, three sisters and three brothers well. His mother has had no miscarriages. No history of syphilis obtainable. The patient had "rheumatism" from the age of 6 months to 3 years. Ever since the age of 3 he has had frequent attacks of hematuria, which occurred only during the winter following exposure to cold. The attack is often accompanied by a chill and followed by fever and pain in the stomach, without subsequent weakness. The hematuria never lasts more than a day. For the past six months he has been gradually losing his eyesight, first of the right, later of the left eye.

Physical Examination: The boy is undersized and only fairly nowrished. Intelligent. Forehead bulging. Interstitial keratitis of both eyes. Teeth suggestive of Hutchinsonian type. Scaphoid scapulae. No glandular enlargement. Spleen and liver just palpable. Both shins show a definite periostitis. There is an effusion into all the large joints. The elbows show a slight limitation of metion.

Blood Examination: Red cells, 4,512,000. White cells, 10,000. Hemoglobin, 81 per cent. (Sahli). Differential count, neutrophils 82 per cent., basophils, 17 per cent., mast cells, 1 per cent. Red cells of normal appearance.

\footnotetext{
* Submitted for publication April 28, 1915.

* From the South Medical Department and the Pathological Laboratory of the Massachusetts General Hospital.

1. Donath and Landsteiner: Ztschr. f. klin. Med., 1906, 1viii, 173.
} 
Platelet count, 345,000. Coagulation time (method of Lee and White, ${ }^{2}$ ) nine minutes - upper limit of normal. Wassermann strongly positive. Urine negative except for hemoglobin after paroxysms, never bile, blood, casts or albumin.

\section{PART I : SERUM REACTIONS}

In view of the suggestion of all those who have worked with the serums of patients suffering from paroxysmal hemoglobinuria, the blood removed for experimentation in this case was kept at a temperature of $37.5 \mathrm{C}$. until ready to be chilled. The same precaution was taken with all other serologic material and organic extracts. For the sake of space and convenience certain symbols are used in our work:
N. H. Sr.
Pt. Sr.
Normal human serum.
Pt. Ch. Sr.
Patient's serum.
Patient's serum which has been chilled with patient's red blood cells at $0 \mathrm{C}$. for one-half hour, centrifuged at the same temperature
Pt. R. B. C. and the clear serum withdrawn.
Pt. W. R. B. C. Patient's washed red blood cells.
N. W. R. B. C. Normal washed red blood cells.
S. W. R. B. C. Sheep's washed red blood cells.
G.-P. Sr.
Guinea-pig serum.
R. Ambo.
Rabbit amboceptor.
In. H. Sr. Anti. Inactivated human serum anticomplementary. C.
Ac.
Pr.
Tr.
Complete hemolysis.
Almost complete.
Partial hemolysis.
Trace.
No hemolysis.

The first experiment consisted of the quantitative demonstration of the autohemolysin and of the native complement, which varied slightly from day to day (Table 1).

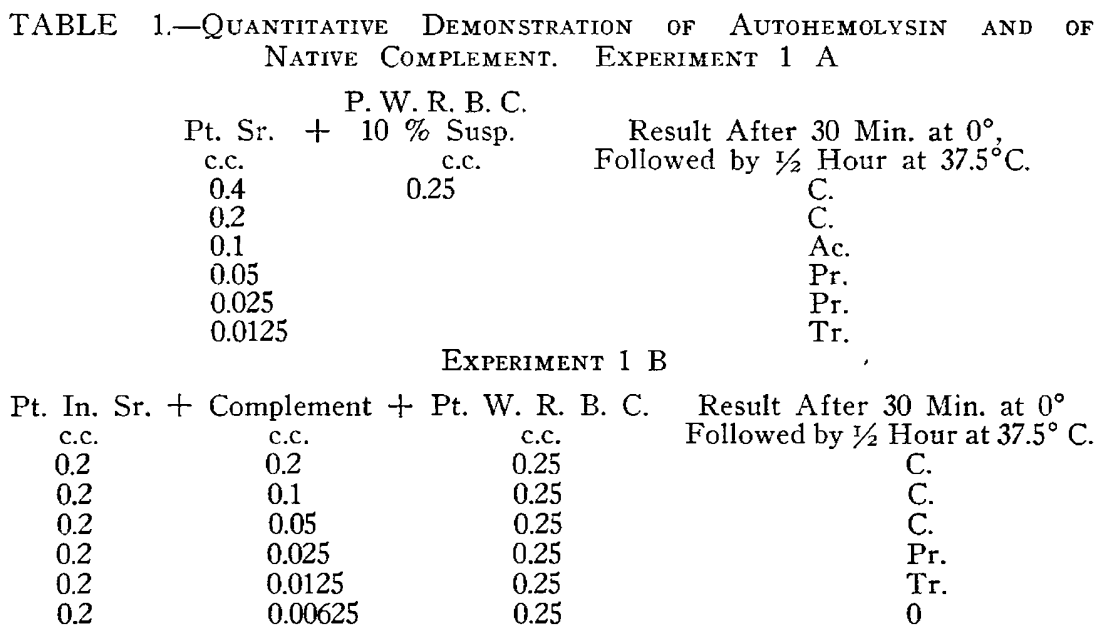

2. Lee and White: Am. Jour. Med. Sc., 1913, clxxii, 495. 
Experiment 1 A shows that 0.2 c.c. of patient's serum is just sufficient to completely hemolyze 0.25 c.c. of patient's washed red blood cells.

Experiment $1 \mathrm{~B}$ shows that the amount of native complement present in 0.2 c.c. of patient's serum is equal to 0.05 c.c. of guinea-pig serum.

It has been stated by many observers, Meyer and Emmerich, ${ }^{3}$ Donath and Landsteiner, $\operatorname{Cook}^{4}$ and others, that the hemolytic amboceptor unites with the patient's red blood cells at $0 \mathrm{C}$. in the absence of complement, then if complement is added later and the test is incubated at $37.6 \mathrm{C}$., hemolysis results. We were unable to confirm this observation. We found that all the different elements must be present throughout the whole reaction, that is, at the low temperature as well as the subsequent incubation at $37.5 \mathrm{C}$., or hemolysis does not take place. This is shown by the experiments recorded in Table 2 .

TABle 2.-Experiments Showing that Hemolysis Does Not Occur Unless All Elements Are Present

\begin{tabular}{|c|c|c|}
\hline \multirow{2}{*}{\multicolumn{2}{|c|}{$\begin{array}{r}\text { Pt.W. R. B. C. } \\
\text { Pt } \mathrm{Sr}+10 \% \text { S.sp }\end{array}$}} & $\begin{array}{l}\text { Result after } 0^{\circ} \text { for } \mathrm{I} / 2 \text { Hour, then } \\
\text { Warmed to } 37.5^{\circ} \mathrm{C} \text {, and } 0.05 \text { c.c. Compl }\end{array}$ \\
\hline & & Added, and Incubated for 1 Hour. \\
\hline 0.4 & 0.25 & $\begin{array}{l}0 \\
0\end{array}$ \\
\hline 0.1 & 0.25 & 0 \\
\hline 0.05 & 0.25 & 0 \\
\hline 0.025 & 0.25 & 0 \\
\hline 0.0125 & 0.25 & 0 \\
\hline
\end{tabular}

After the complement was added to each of the tubes previously warmed to $37.5 \mathrm{C}$. and kept at $37.5 \mathrm{C}$. for one hour, no hemolysis took place. Each element in turn was left out with the same result. If the complement is added to the tubes before they are warmed up to blood heat, strong hemolysis occurs for the simple reason that the union of these elements takes place in a few minutes in the cold, not necessarily at $0 \mathrm{C}$. It is obvious that it will require several minutes after the tubes have been placed in the incubator at $37.5 \mathrm{C}$. to raise the temperature from 0 to $37.5 \mathrm{C}$. Thus, we found that in our experiments all elements must be present at a temperature below $37.5 \mathrm{C}$. in order that hemolysis might occur. This result agrees with the findings of Moss $^{5}$ and Hoover and Stone. ${ }^{6}$

Again, it is asserted by other investigators, Widal, Abrami and Brissaud, ${ }^{7}$ that there exists in the serum of patients suffering from

3. Meyer and Emmerich: Deutsch. Arch. f. klin. Med., 1909, xcvi, 287.

4. Cook: Am. Jour. Med. Sc., 1912, cxliv, 203.

5. Moss: Johns Hopkins Hosp. Bull., 1911, xxii, 229.

6. Hoover, C. F., and Stone, C. W.: Paroxysmal Hemoglobinuria, ThE Archives Int. Med., 1908, ii, 392.

7. Widal, Abrami and Brissaud: Compt. rend. Soc. de biol., 1913, 1xxv, 502. 
paroxysmal hemoglobinuria an inhibitory substance which prevents the union of the hemolytic bodies with the patient's red blood cells at $37.5 \mathrm{C}$., but which is inactive at lower temperature, thus allowing this combination to take place. It occurred to us that if such an inhibiting substance were present in the serum and could be isolated, it should exert a restraining influence on other hemolytic systems if brought into the proper relations with them. A plan was devised for isolating this substance, if it existed, and using it against the sheeprabbit hemolytic system. Conceding that this inhibiting element is active at blood temperature and inactive at lower temperatures, it should remain free in the centrifuged fluid if the hemolytic amboceptor is given a chance to unite with the patient's red blood cells in the cold. This we attempted to do in the following experiments:

Two c.c. of patient's serum plus 0.25 c.c. of patient's washed red blood cells 100 per cent. suspension was chilled for one-half hour at $0 \mathrm{C}$., centrifuged at the same temperature and the clear supernatant fluid withdrawn. This fluid should now contain the hemolytic inhibiting bodies free in solution, and if used against the other hemolytic systems might reasonably be expected to prevent their union. We were fortunate enough to have the serum of a patient which at this time and many times previously contained a serologic substance occurring in a sufficient amount in 0.2 c.c. of serum to prohibit absolutely the hemolysis of sheep's washed red blood cells by sensitized rabbit's serum, and this was used as a control in the experiment given in Table 3. For the sake of convenience the control experiment will be given first.

TABLE 3.-Control Experimant

$\begin{array}{ccc}\text { In H. S. } & +5 \% \text { Susp., } & \text { Result After Adding 1 Unit } \\ \text { Anti. } & \text { S. W. R. B.C. } & \text { R. Ambo. and Incubating } \\ \text { c.c. } & \text { c.c. } & \text { I/2 Hour at } 37.5^{\circ} \\ 0.4 & 0.5 & 0 \\ 0.2 & 0.5 & 0 \\ 0.1 & 0.5 & 0 \\ 0.05 & 0.5 & 0 \\ 0.025 & 0.5 & 0 \\ 0.0125 & 0.5 & 0\end{array}$

Result
A $\mathrm{f}$ e r Adding 0.05
Compl. and Incubat-
ing 1 Hour at $37.5 \mathrm{C}$.
0
0
Sl.
Pr.
Str.

Before the complement was added, the tubes were incubated for one-half hour at $37.5 \mathrm{C}$. There was no hemolysis at the end of this time (which was to be expected). This merely demonstrates the absence of complement. After the complement was added and the tubes incubated for one hour, 0.2 c.c. of this so-called anticomplementary serum was sufficient to prevent completely the hemolysis in the sheep-rabbit system. Smaller amounts allowed some hemolysis to take place for the reason that the anticomplementary substance was present in very small amounts. The serum used as a control had no natural 
sheep's red blood cell hemolysins, while the blood of the patient did contain such substances.

The foregoing experiment was repeated, the supernatant fluid removed from the cold-warm experiment being used instead of the anticomplementary serum.

\begin{tabular}{|c|c|c|c|}
\hline & & to Show the AbSence of & IN HIBITORY BODIES \\
\hline Ch. S & $\begin{array}{l}\text { W. S. R. B. C. } \\
+5 \% \text { Susp. }\end{array}$ & $\begin{array}{l}\text { Result After Adding } 1 \text { Unit } \\
\text { R. Ambo. and Incubating }\end{array}$ & $\begin{array}{l}\text { Result } \\
\text { A f t e r Adding } 0.05 \\
\text { c.c. Compl., Incub. }\end{array}$ \\
\hline & c.c. & $1 / 2$ Hour at $37.5^{\circ}$ & 1 Hour at $37.5 \mathrm{C}$. \\
\hline 0.4 & 0.5 & 0 & $\mathrm{C}$ \\
\hline 0.2 & 0.5 & $\begin{array}{l}0 \\
0\end{array}$ & C \\
\hline 0.1 & $\begin{array}{l}0.5 \\
0.5\end{array}$ & $\begin{array}{l}0 \\
0\end{array}$ & $\stackrel{C}{C}$ \\
\hline 0.05 & 0.5 & $\begin{array}{l}0 \\
0\end{array}$ & $\stackrel{\mathrm{C}}{\mathrm{C}}$ \\
\hline 0.0125 & 0.5 & 0 & $\mathrm{C}$ \\
\hline
\end{tabular}

The complete hemolysis in all the tubes at the end of an hour demonstrated that the supernatant fluid used possessed no inhibiting properties. This evidence was further supported by the fact that the patient's serum possessed a very strong natural hemolysis for sheep's washed red blood cells which was in no way affected by these supposedly inhibiting substances.

From these experiments we must conclude that if there is a restraining substance present in the serum of hemoglobinurics which prevents the uniting of the specific substances at body temperature, it does not act in the same way on other hemolytic systems, since it did not in the least prevent the complete hemolysis of sheep's washed red blood cells by sensitized rabbits serum. On the other hand, 0.2 c.c. of a serum containing a known inhibitory substance did absolutely prevent the hemolysis of sheep's washed red blood cells. Furthermore, such a restraining substance did not exist in the serum of the patient suffering from paroxysmal hemoglobinuria. The physical and chemical composition of the autohemolytic amboceptor was such that it would not unite with the patient's washed red blood cells except it first be subjected to cold.

\section{PART II: UROBILIN AND HEMOGLCBIN EXCRETION}

It has been shown by several investigators (Wilbur and Addis, ${ }^{8}$ Eppinger and Charnas ${ }^{9}$ and by one of $\mathrm{us}^{10}$ ) that the quantity of urobilin in the stool may be taken as an index of blood destruction. Blood destruction is greatly increased in diseases which show an abnormal amount of hemolysis going on in the body, as pernicious anemia, congenital hemolytic jaundice, etc. Quantitative estimations for uro-

8. Wilbur, R. L., and Addis, Thomas: Urobilin: Its Clinical Significance, The Archives Int. Med., 1914, xiii, 235.

9. Eppinger and Chamas: Arch. f. klin. Med., 1913, 1xxxiii, 387.

10. Robertson, O. H.: The Archives Int. Med., to be published. 
bilin $^{11}$ were made on the stools of this patient with the expectation of demonstrating an increased output following each paroxysm. Much to our surprise, there was practically no change in the quantity of urobilin excreted during two weeks in which he was given three exposures to cold, all of which were followed by hemoglobinuria. The absence of any increase could be explained in only two ways: first, that the amount of blood hemolyzed at each exposure was comparatively small, and second, that the kidney threshold for hemoglobin was very low, thus permitting a rapid excretion of this substance.

In order to determine the quantity of free hemoglobin in the blood serum and urine, a colorimetric method with a standard solution of hemoglobin was used. The standard solution, that is, one containing a known quantity of hemoglobin, was made by adding 10 c.c. of fresh blood to 100 c.c. of tenth-normal hydrochloric acid, which changed the oxyhemoglobin completely into hematin hydrochlorate, a more stable colorimetric solution. It was then diluted up to 1,000 c.c. with distilled water, thus producing a color suitable to work with. Finally the solution was centrifugated clear. The amount of hemoglobin per cubic centimeter of solution was determined in the following way: Sahli's hemoglobinometer was originally made up by using the blood of one or several individuals whose hemoglobin was 17.2 per cent. of the total blood weight. Thus a blood reading 100 per cent. on the Sahli scale would have $17.2 \mathrm{gm}$. of hemoglobin per hundred grams of blood. The patient from whom the blood for the standard was taken had a hemoglobin of 40 per cent.; therefore each hundred c.c. would contain 40 per cent. of 17.2 , or $6.88 \mathrm{gm}$. Ten c.c. would contain $0.688 \mathrm{gm}$., and when diluted to 1,000 c.c. each cubic centimeter would contain $0.000688 \mathrm{gm}$. of hemoglobin.

The experiment was carried out as follows: Both feet and half the lower legs were immersed in ice water for five minutes. After eight minutes, 10 c.c. of blood were withdrawn from an arm vein into 1 c.c. of 1 per cent. sodium oxalate solution. The boy was urged to micturate every few minutes. After forty minutes he had a slight chill and passed a few drops of deeply blood-tinged urine. Ten c.c. more blood were then taken. The blood in each instance was kept at body temperature from the time it left the vein until the serum had been separated from the corpuscles by centrifugation. This precaution was observed in order to prevent further hemolysis due to cooling. The second specimen of serum was much more deeply tinged with hemoglobin than the first, which was accordingly discarded. Two hours after the exposure to cold, he passed 23 c.c. of purplish-black urine. During the next two and a half hours he was given three

11. The method used was that of Wilbur and Addis (Footnote 8). 
glasses of water in order that all hemoglobin might be washed out of the bladder. At the end of this time he passed 100 c.c. more urine only slightly blood tinged. That this was the last specimen to show any hemoglobin was indicated by the fact that a clear urine giving a negative guaiac test was obtained at each later passage.

To the blood serum were added $31 / 2$ times its volume of tenthnormal hydrochloric acid, which was quite sufficient to change all the oxyhemoglobin into hematin hydrochlorate. The mixture was next centrifugated to throw down any suspended material. It was then read against a $1: 2,000$ dilution of the standard solution. After the addition of a few drops of lead acetate to each of the two separate specimens of urine, they were filtered. In this way all organic matter except hemoglobin was removed. Then, in order to insure against any loss of hemoglobin, the precipitate was washed with tenth-normal hydrochloric acid in a quantity equal to three or four times the amount of urine, and these washings added to the urine just filtered. Each urine solution which was quite clear was then read against a dilution of the standard solution somewhere near its color.

It was found that each cubic centimeter of the boy's blood contained $0.000592 \mathrm{gm}$. of hemoglobin, and this multiplied by his total blood volume, which was estimated at 1,507 c.c., using $1: 19$ as the ratio of blood weight to body weight, gave a total amount of $0.862 \mathrm{gm}$. The first specimen of urine contained $0.79 \mathrm{gm}$., which represented the hemoglobin excreted in the first two hours. The second specimen contained $0.04 \mathrm{gm}$., representing that excreted during the next two and one-half hours. The sum of the two, $0.83 \mathrm{gm}$., gives the total quantity of hemoglobin excreted in four and one-half hours. Calculating it in per cent., we find that he excreted in the first two hours 91.7 per cent. of the entire hemoglobin set free, and in four and onehalf hours, 96.3 per cent.

It was also very simple to estimate just how much blood $0.862 \mathrm{gm}$. of hemoglobin represented. His blood showed a hemoglobin of 81 per cent.; using the Sahli scale again, 81 per cent. of 17.2 equals 13.9 ; that is, each 100 c.c. of blood contains $13.9 \mathrm{gm}$. of hemoglobin, 1 c.c. containing 0.139 gm., $0.862 \div 0.139=6.3$ c.c. of blood hemolyzed.

This exceedingly rapid excretion of hemoglobin accounts for the low urobilin output by the fact that the liver is given very little opportunity to transform the circulating hemoglobin into bile, which is in turn broken down in the intestine into urobilin. Even if the hemoglobin had not been excreted so rapidly, it is questionable whether the relatively small amount of hemoglobin set free would have produced a noticeable change in the amount of urobilin in the stool. 
The apparent marked hemoglobinuria can be explained in the same way, namely: by the very low kidney threshold for hemoglobin and its prompt excretion. The small amount of blood destroyed by the short but intense experimental exposure demonstrates that he could stand a great deal of cold without danger to life.

We realize that this method had its sources of error, the chief one being that it was impossible to judge the exact time after the paroxysm when the concentration of hemoglobin in the blood serum would be at a maximum. The time chosen may have been a little late, and some of the hemoglobin may have been excreted already; but as far as we could tell, he had excreted only a very small amount. We did not feel justified in bleeding him oftener at this time.

\section{SUM MARY}

The patient was a congenital syphilitic with characteristic physical findings and a strongly positive Wassermann.

The patient suffered from paroxysmal hemoglobinuria with typical attacks following exposure to cold.

These attacks could be induced at any time.

The characteristic hemolysis occurred under proper conditions in the test.

It was shown by experiments that the patient's serum, red blood cells and complement must be present throughout the whole reaction, or hemolysis will not take place.

The failure of the hemolytic reaction to take place unless the elements are first chilled together is not due to an inhibiting substance which is active at blood temperature but inactive in the cold, as the sheep-rabbit system is in no way affected when brought into proper relation with this system. The failure is probably due to the peculiar make-up of the hemolytic amboceptor.

The hematuria following a moderately severe experimental exposure to cold resulted from the destruction of only approximately 6.3 c.c. of blood.

Over 90 per cent. of the hemoglobin set free was excreted in the urine within two hours, and 96 per cent. in four and one-half hours.

The very rapid excretion of hemoglobin by the kidneys probably explains the absence of any increased amount of urobilin in the stools. 